\title{
0 CORDEL NA CONTEMPORANEIDADE \\ A PERSEVERANÇA DE UM SÍMBOLO DA IDENTIDADE NORDESTINA NUMA SOCIEDADE DE MULTIMEIOS
}

Katja Pryscilla Cunha Martins Augusto (Univ. de Coimbra)

Este artigo visa refletir sobre as origens da literatura de cordel e os motivos pelos quais chegou à internet. Tendo em vista a globalização e os meios de comunicação de massa, procura-se aqui analisar de que forma esses fenômenos incidiram sobre as identidades locais, se positiva ou negativamente. $O$ texto discorre sobre os mecanismos encontrados pelas instituições, em geral, e pelos poetas, em particular, para que o cordel, símbolo da cultura da Região Nordeste do Brasil, persista na sociedade fragmentada e multimidiática.

\section{CORDEL; IDENTIDADE; INTERNET.}

AUGUSTO, Katja Pryscilla Cunha Martins. O cordel na contemporaneidade: a perseverança de um símbolo da identidade nordestina numa sociedade de multimeios. Textos escolhidos de cultura e arte populares, Rio de Janeiro, v.10, n.1, p. 7-17, mai. 2013. 


\section{THE CORDEL IN CONTEMPORARY TIMES \\ THE PERSEVERANCE OF A SYMBOL OF NORTHEASTERN IDENTITY IN A MULTIMEDIA SOCIETY}

Katja Pryscilla Cunha Martins Augusto (Univ. de Coimbra)

This article aims at reflecting upon the origins of the pamphlet literature (cordel) and the reasons why it has reached the internet. Given the globalization and means of mass communication, we intend to analyze how these phenomena affected local identities, whether positively or negatively. The text discusses the mechanisms encountered by institutions in general, and poets in particular, so that the cordel, symbol of the culture of the Brazilian Northeast, can endure in a fragmented and multimidiatic society.

CORDEL; IDENTITY; INTERNET.

AUGUSTO, Katja Pryscilla Cunha Martins. O cordel na contemporaneidade: a perseverança de um símbolo da identidade nordestina numa sociedade de multimeios. Textos escolhidos de cultura e arte populares, Rio de Janeiro, v.10, n.1, p. 7-17, mai. 2013. 


\section{INTRODUÇÃO}

Chegamos a um momento em que qualquer informação que busquemos, seja lúdica ou científica, está à distância de alguns cliques. A internet, como meio de comunicação, sobressai dos demais tanto por sua capacidade infinita de armazenar dados quanto por ser um veículo multimidiático. Devido a suas características, entre elas o controle do internauta sobre a informação que recebe, diferentemente do que acontece com a mídia de massa, os grandes veículos comunicacionais sentiram-se obrigados a migrar para a grande rede, já que esse novo meio passou a atrair mais público e mais receitas publicitárias. Diante desse cenário, cabe indagar se a passagem da literatura de cordel nordestina, inicialmente um veículo de comunicação das classes populares, foi fruto de uma migração com vistas à sobrevivência.

Uma vez que não foi encontrado qualquer trabalho publicado que respondesse a essa questão, tornou-se oportuna a realização deste artigo. 0 método de pesquisa utilizado foi a elaboração de um questionário, enviado por e-mail a algumas personalidades do mundo do cordel, além da busca de bibliografia sobre esse tipo de literatura e sobre cultura e identidade. Responderam ao questionário Maria do Rosário Pinto, do Centro Nacional de Folclore e Cultura Popular/Iphan/MinC e membro da Academia Brasileira da Literatura de Cordel; César Obeid, escritor, educador e contador de histórias; Chico Salles, cordelista e forrozeiro; e Paulo Barja, professor universitário, músico e cordelista. Seus contributos e a orientação da professora doutora Maria Aparecida Ribeiro, da Universidade de Coimbra, foram fundamentais para o resultado desta exposição.

\section{OS PRIMÓRDIOS DA GLOBALIZAÇÃO E A CHEGADA DO CORDEL AO BRASIL}

O processo de globalização ao qual o mundo está submetido teve seu início com as grandes navegações europeias do século $X V$ e a respectiva expansão marítima, com vistas à busca de novas rotas comerciais e novos mercados. Ao longo do caminho por onde as frotas iam passando, territórios foram conquistados, e colônias fundadas não só para estabelecer trocas de mercadorias com os povos locais, mas também para submeter os nativos e as terras à exploração. Dessa atuação, entre outras consequências, resultou uma das maiores diásporas de sempre, com a instauração do tráfico de africanos, em especial para o continente americano.

Paralelamente a essa migração forçada, houve a saída de europeus em direção às colônias que seus países estabeleciam pelo mundo, ou em busca de ri- 
quezas ou apenas à procura de uma vida melhor. A América portuguesa, que mais tarde foi batizada de Brasil, foi uma das regiões em que o impacto da conquista territorial foi intenso não só pelo encontro de índios, africanos e europeus, principalmente portugueses, mas também pela escravização e cristianização dos nativos e dos negros. Segundo os colonizadores, esses processos eram considerados fundamentais para a civilização daqueles povos.

Nas bagagens desses povos que se transladaram para o Brasil, vieram seus costumes e crenças, que, depois de terem aportado no Novo Mundo, foram reinventados e adaptados àquilo que o local oferecia. Um desses itens foi a literatura de cordel, trazida pelos portugueses, cujo nome deve-se antes à forma como esses folhetos eram vendidos, pendurados num barbante, do que propriamente ao estilo literário. Era, portanto, uma fórmula editorial, comum na Europa, para a divulgação de textos de variadíssimos gêneros, de preço acessível aos setores da população menos intelectualizados e com menos recursos financeiros.

O cordel em Portugal não tinha forma textual específica. Ao contrário, sua tipologia era bastante heterogênea, uma vez que reunia tanto textos em prosa ou em verso quanto peças teatrais, e, no que tange ao conteúdo, podiam ser traduções ou adaptações de grandes obras literárias estrangeiras ou publicações de autores nacionais populares ou eruditos. Quanto à materialidade, não passavam de folhetos de poucas páginas e feitos com papel barato. Esses folhetins foram levados pelos emigrantes portugueses para o Brasil e lá comercializados. Entretanto, em terras tupiniquins, os textos escritos em prosa, construídos "com períodos longos, com sintaxe distinta da fala coloquial, sem apoios para a memória, como recorrências sonoras ou ritmos marcados" (ABREU, 1999, p. 72), foram sintetizados e transformados em versos com o intuito de facilitar a assimilação pela população analfabeta e, consequentemente, a transmissão entre gerações.

As histórias vindas da Europa eram assim contadas no Nordeste brasileiro pela figura do cantador - um nômade, quase sempre analfabeto ou semianalfabeto, que havia abandonado a família para percorrer os sertões. Paralelamente, tendo em vista que a informação, àquela época, era também transmitida oralmente, cabia a essa personagem a incumbência de divulgar, também em forma versada,

versões coloridas de fatos e "causos", versões que respondem aos instintos de revolta ou às esperanças da população desassistida e ignorante de hinterlândia: estórias de "milagres" de beatos e penitentes, de aparições de almas de outro mundo recomendando que se faça isto ou aquilo, de mortes cometidas em defesa da honra da família ou em retribuição a injustiças e roubos de que são vítimas 
os pequenos proprietários rurais, a distribuição dos bens dos ricos com os pobres por cangaceiros e "santos", que criam fama de heróis, como Antônio Silvino, como Lampião, como Padre Cícero do Juazeiro (BELTRÃo, 1971, p. 48).

Dadas a popularidade e a notoriedade dos cantadores entre o público daquela região, não foi preciso muito para que seus versos e improvisos fossem transpostos para o folheto impresso. Essas pequenas brochuras, de oito a 32 páginas, começaram a ser comercializadas em mercados e feiras, e o folheteiro, para estimular a venda, aproveitava os momentos de maior concentração de pessoas, que o rodeavam para ouvir suas histórias. E "quando [a assistência] gosta do romance ou quando o acontecimento lhe chama a atenção, compra o folheto, leva-o consigo para soletrá-lo à família ou pedir que alguém alfabetizado o leia de novo, até decorar as sextilhas" (BELTRÃo, 1971, p. 67).

Com o passar do tempo, os poetas cordelistas nordestinos foram aprimorando a forma, estabelecendo regras quanto à estrutura, à métrica e à rima. Por esse e outros motivos, há quem conteste que a literatura de cordel daquela região tenha origem na que já era produzida na metrópole, pois

Nada nesse processo parece lembrar a literatura de cordel portuguesa. Aqui [no Brasil], havia autores que viviam de compor e vender versos; lá [em Portugal], existiam adaptadores de textos de sucesso. Aqui, os autores e parcela significativa do público pertenciam às camadas populares; lá, os textos dirigiam-se ao conjunto da sociedade. Aqui, os folhetos guardavam fortes vínculos com a tradição oral, no interior da qual criaram sua maneira de fazer versos; lá, as matrizes das quais se extraíam os cordéis pertenciam, de longa data, à cultura escrita. Aqui, boa parte dos folhetos tematizavam o cotidiano nordestino; lá, interessavam mais as vidas de nobres e de cavaleiros. Aqui, os poetas eram proprietários de sua obra, podendo vendê-la a editores, que por sua vez também eram autores de folhetos; lá, os editores trabalhavam fundamentalmente com obras de domínio público (ABREU, 1999, p. 104).

Se a origem dos cordéis nordestinos não pode ser atribuída a Portugal, como argumenta Márcia Abreu em sua tese intitulada Histórias de cordéis e foIhetos, a autora se contradiz não só quando afirma que as histórias em prosa dos folhetos portugueses foram "adaptadas" ao estilo normatizado pelos poetas do Nordeste, como também quando cita que a materialidade foi "mantida" tal e qual à portuguesa, que por sua vez pode ter sido copiada de outras regiões. Contestar a posição de Abreu não significa, entretanto, que o extremo oposto seja o verdadeiro, isto é, que a literatura dos colonizadores tenha sido aceita passivamente; 
ao contrário, foi alvo de antropofagismo, ou seja, devorada criticamente e transformada em novo produto. As influências portuguesas, que não podem ser negadas, aliadas à criatividade dos colonos conferiram, assim, identidade própria à literatura de cordel produzida no Brasil.

\section{A QUESTÃO DA IDENTIDADE}

A literatura de cordel e a forma pela qual é construída refletem a cultura de um povo, a qual também é moldada pelas condições sociais a que está submetido. O modo como tal povo relaciona seu interior com o mundo exterior, ou seja, os sentimentos subjetivos com os espaços objetivos da sociedade e do mundo, constitui a identidade. À identidade, cabe, portanto, a função de costurar o indivíduo à estrutura, "estabiliza[ndo] tanto os sujeitos quanto os mundos culturais que eles habitam, tornando ambos reciprocamente mais unificados e predizíveis" (HALL, 2001, p. 10).

A literatura de cordel nordestina, cuja função não se restringia à diversão, pois também era uma forma de transmitir informação, constitui aquilo que Luiz Beltrão chama de folkcomunicação, isto é, um mecanismo de comunicação próprio dos menos favorecidos. Era um canal adaptado à realidade e às demandas locais, de caráter artesanal e com linguagem própria, que, ao mesmo tempo suprimia a escassez de outros veículos de comunicação e revelava a cultura popular.

Talvez caiba aqui diferenciar a cultura popular da nacional. A cultura nacional, como afirma Stuart Hall (2001), é um discurso que tem por finalidade unir os diferentes grupos sociais que constituem uma nação em torno da mesma identidade. Onde, porém, houve processos de conquista violenta e de imposição cultural, a construção de identidade única, que representasse a sociedade como um todo, foi comprometida. O mesmo aconteceu nas regiões que foram colonizadas e formadas por uma elite, minoria, e por um povo em condições de vida precárias, com restrito acesso às necessidades básicas, como educação, saúde etc. Nestes e naqueles casos, em vez de uma cultura comum a todos os grupos que compõem a nação, verifica-se a presença de numerosas culturas e identidades. O Brasil é exemplo dessa realidade: com suas dimensões continentais, seu povo bastante heterogêneo e seus antagonismos, é um híbrido cultural.

Com o fenômeno da globalização, entretanto, a cultura e a identidade nacionais são, num primeiro momento, impactadas, principalmente nos países não hegemônicos, onde, desde os tempos de colônia, a elite local sempre apreciou e tentou imitar os costumes e as modas da metrópole. Com a intensificação do processo, "à medida em que áreas diferentes do globo são postas em interconexão 
umas com as outras, ondas de transformação social atingem virtualmente toda a superfície da terra" (GUIDDENS apud HALL, 2001, p. 15), e a sociedade é alvo de um deslocamento contrário a sua matriz cultural.

Quanto à sociedade, em geral, e aos grupos sociais mais desfavorecidos, em particular, se, no passado, o contato com a realidade exterior se limitava à localidade, a globalização e a universalização dos meios de comunicação de massa permitiram o acesso a outras e mais informações, a interação com outras sociedades, mesmo que a distância, e a expansão do conhecimento individual. Uma das principais consequências dessa mudança incide sobre a forma como o sujeito lê o mundo e o concebe, fato que, automaticamente, afeta a construção de sua identidade. Se antes ela era "unificada e estável", o indivíduo de agora, da pós-modernidade, é "fragmentado", "composto não de uma única, mas de várias identidades, algumas vezes contraditórias ou não resolvidas" (HALL, 2001, p. 11).

A identidade torna-se uma "celebração móvel": formada e transformada continuamente em relação às formas pelas quais somos representados ou interpelados nos sistemas culturais que nos rodeiam. É definida historicamente, e não biologicamente. O sujeito assume identidades diferentes em diferentes momentos, identidades que não são unificadas ao redor de um "eu" coerente. (...) à medida que os sistemas de significação e representação cultural se multiplicam, somos confrontados por uma multiplicidade desconcertante e cambiante de identidades possíveis, com cada uma das quais poderíamos nos identificar - ao menos temporariamente (p. 12-13).

No aspecto cultural, um dos grandes contribuidores, senão o maior, para a dispersão das referências foram - e ainda são - os Estados Unidos, com a difusão do american way of life além de suas fronteiras territoriais. O glamour e a virilidade dos personagens de filmes de Hollywood encantaram e influenciaram gerações de meados do século XX em diante, para as quais cinema constituía uma das melhores diversões de fim de semana. Com a expansão do capitalismo e dos mercados, a transnacionalização de empresas e marcas fez com que cidadãos de quase todo o mundo, quase que independentemente do lugar onde estivessem, tivessem gostos iguais, pudessem consumir produtos iguais, dando a impressão de aculturação, de homogeneização. A indústria cultural tem peso significativo nesse processo, pois contribuiu para que o sujeito simpatizasse e até se identificasse mais intensamente com culturas diferentes da sua do que com a própria. Como bem sintetiza Néstor Canclini (2005, p. 41), em sua obra Consumidores e cidadãos, quando se refere ao novo cenário sociocultural, 
O que é novidade na segunda metade do século XX é que estas modalidades audiovisuais e massivas de organização da cultura foram subordinadas a critérios empresariais de lucro, assim como a um ordenamento global que desterritorializa seus conteúdos e suas formas de consumo. A conjugação das tendências desreguladoras e privatizantes com a concentração transnacional das empresas diminui as vozes públicas, tanto na "alta-cultura" como na popular.

Por outro lado, ao mesmo tempo que a globalização sugere um padrão ideal de vida e de consumo, verifica-se também um fascínio pelo local, pelo característico, pela alteridade não apenas para preservar a memória antepassada, mas também, e principalmente, como forma de, em meio à homogeneização global, nos distinguirmos em face do outro. A literatura de cordel é um desses elementos que persiste na cultura brasileira, em especial na nordestina, para que um dos símbolos que marcam a identidade da região não se perca. Nesse sentido, a par da criação de instituições e acervos por todo o país com o objetivo de reunir foIhetos e outros materiais que representam essa cultura, poetas de várias regiões dão continuidade a essa tradição ao se dedicar à elaboração de cordéis.

\section{A LITERATURA DE CORDEL EM PLENO SÉCULO XXI}

A literatura de cordel no Brasil, no início, estava ligada aos grupos sociais mais pobres do Nordeste - ou "marginalizados", como afirma Alfredo Dias D’Almeida (2003). Com suas raízes na oralidade, a partir dos anos 40 com Sebastião Nunes Batista e Rogaciano Leite, entre outros, e mais intensamente nas últimas décadas do século XX, essa literatura deixou de ficar restrita às camadas populares; ao contrário, pessoas com formação escolar e intelectuais passaram a compor cordéis. Segundo Maria Rosário Pinto, "a literatura cordelística não tem caráter temporal, visto que atualiza-se constantemente; é das poucas manifestações que atravessa os tempos". Prova disso é sua utilização em propostas educativas e pedagógicas e em campanhas de alerta. Nas palavras de Chico Salles,

O cordel Contemporâneo não caduca, / Antenado no que é cotidiano / O seu tema tem o tino soberano / Bota a mão no fogo e na cumbuca / Às vezes ele fere, não machuca / Traz no texto o desejo dos amantes / Sua bandeira hasteada aos estudantes / Representa também o descontente / O cordel brasileiro é resistente / Aos descasos culturais dos governantes.

A par das histórias ficcionais contadas pelo poeta cordelista, os acontecimentos também captam a sua atenção, sejam eles regionais, nacionais ou internacionais. Nesse sentido, pode-se dizer que a universalização dos veículos de comunicação, ao permitir o aumento de fluxo e recepção de informação, benefi- 
ciou o cordelista, uma vez que ampliou a temática para elaboração de cordéis. Se personalidades do mundo de cordel como Costa Leite acreditam que as produções televisivas de entretenimento podem ter desviado a atenção do público em benefício próprio (DINIZ, s/d), outras defendem que as mídias de massa em nenhum momento afetam negativamente a literatura de cordel. São vários, aliás, os programas de televisão e rádio dedicados a essa literatura. De acordo com César Obeid, "hoje o poeta aproveita, quando pode, os meios de comunicação para fortalecer a sua arte".

O mesmo acontece quando se trata da internet. No lugar de um meio de sobrevivência e manutenção da arte, essa nova mídia, cuja existência não deve ser desprezada, fortalece e complementa o próprio folheto impresso. Na visão de Paulo Barja, os motivos pelos quais os cordelistas usam a grande rede residem no fato de esse veículo facilitar a divulgação do trabalho, ampliar a circulação das obras e permitir o estabelecimento de contato entre autores, público e demais interessados na literatura de cordel. A própria internet, além de ferramenta, é tema de trabalho, como se verifica no seguinte trecho do "Cordel do Software Livre", de Cárlisson Galdino (s/d):

Computador e internet / Vivem no nosso Presente / Mesmo sendo tão ligados / Cada um é diferente / Mas toda coisa criada / Não serviria pra nada / Se não fosse para gente

São vários os poetas cordelistas que, sem ter aberto mão das publicações em formato impresso, têm sites próprios onde publicam suas obras. A web, como janela para o mundo, permite que qualquer indivíduo, de qualquer lugar, desde que munido dos dispositivos necessários e de uma conexão, acesse tal conteúdo. O sucesso da internet deve-se, justamente, não só a esse, mas também a outros motivos: além da abolição das distâncias na busca de informação, há o encurtamento do tempo comparado a outras mídias para divulgação das notícias, o estabelecimento e a manutenção do contato com outras pessoas (o que já era possível com o telefone, mas agora de maneira mais simples) e, principalmente, a possibilidade de qualquer sujeito ser produtor e difusor de conteúdo.

É especialmente o último ponto que, aliado aos demais, possibilita a propagação e o fortalecimento de uma literatura típica da cultura da região nordestina, muitas vezes mais do que a reunião das obras num único espaço, pois o acesso a este acaba por ser condicionado pelo deslocamento. Tendo ciência dessa realidade, instituições que se dedicam a esse fim, como o Centro Nacional de Folclore e Cultura Popular, no Rio de Janeiro, o Acervo Maria Alice Amorim, em Pernambuco, ou a Biblioteca Belmonte, em São Paulo, entre outras, criaram pá- 
ginas na internet, com o intuito de divulgar seus acervos e o trabalho que desenvolvem, o que Ihes traz, em contrapartida, valor e visibilidade.

\section{CONCLUSÃO}

A literatura de cordel não pode ser tida como genuinamente nordestina ou uma cópia daquela que era composta em Portugal. Ao contrário, o cordel foi reinventado no Brasil, a partir do momento em que foi adaptado à realidade do povo que habitava aquela região. Foi, portanto, alvo de um processo de transculturação, cujo resultado se refletiu na concepção de um dos símbolos da identidade do Nordeste.

A própria ida do cordel para o Brasil, levado pelos portugueses, é uma das provas de que o processo de globalização, nesse caso, cultural, não é fenômeno tão recente quanto se possa pensar. É certo que sua intensificação se deu com o aumento da mobilidade das pessoas e, principalmente, com a universalização dos meios de comunicação, mas seu marco inicial está nas grandes navegações ou até mesmo, em escala menor, nas Cruzadas - com as interações entre os diferentes povos.

Sem dúvida, a rede mundial de computadores reforça esse processo. Contudo, antes de favorecer a homogeneização cultural da população mundial, potencializa as identidades locais, uma vez que, por ser um espaço livre, permite que símbolos culturais sejam propagados e divulgados pelo mundo. Por esse motivo, a internet surge como um complemento das obras dos poetas cordelistas, que, assim, são dadas a conhecer a um público maior - ao contrário dos folhetos impressos, cuja circulação é limitada pelo espaço e pela tiragem.

\section{REFERÊNCIAS BIBLIOGRÁFICAS}

ABREU, Márcia. Histórias de cordéis e folhetos. Campinas: Mercado das Letras, 1999.

BELTRÃO, Luiz. Comunicação e folclore: um estudo dos agentes e dos meios populares de informação e expressão de ideias. São Paulo: Melhoramentos, 1971.

CANCLINI, Néstor García. Consumidores e cidadãos. 5. ed. Rio de Janeiro: Editora UFRJ, 2005.

COUTINHO, Eduardo F. "Reconfigurando identidades: literatura comparada em tempos pós-coloniais na América Latina". In: BUESCO, Helena et al. (Org.). Floresta encantada: novos caminhos da literatura comparada. Lisboa: Publicações Dom Quixote, 2001.

D’ALMEIDA, Alfredo Dias. "Folkmídia: a mediação da cultura popular pelos meios de comunicação de massa, de Beltrão a Luyten". PCLA, v. 4, n. 3, abr.-jun. 
2003. Disponível em: http://www2.metodista.br/unesco/PCLA/revista15/ artigos\%2015-4.htm. Acesso em 24.11.2010.

DINIZ, Madson Góis. "Do folheto de cordel para o cordel virtual: interfaces hipertextuais da cultura popular". Disponível em: http://www.ufpe.br/nehte/revista/artigo11-madson-gois.pdf. Acesso em: 24.11.2010.

GALDINO, Cárlisson. "Cordel do Software Livre". Disponível em: http://mundocordel.blogspot.com/search/label/Internet Acesso em: 5.01.2011.

HALL, Stuart. A identidade cultural na pós-modernidade. Rio de Janeiro: DP\&A, 2001.

Katja Augusto é graduada em comunicação social - jornalismo (2008) e pósgraduada em mídias digitais (2010), ambas pela Universidade Estácio de Sá. Atualmente é doutoranda em ciências da comunicação na Universidade de Coimbra e graduanda em história na Universidade Federal Rural do Rio de Janeiro.

Recebido em: 07/04/2013

Aceito em: 01/05/2013 
